\title{
The JLO in colour
}

'Mere colour, unspoiled by meaning, and unallied with definite form, can speak to the soul in a thousand different ways', so said Oscar Wilde. The importance of colour in the appreciation of information is universally recognised. For that reason, we at The Journal of Laryngology \& Otology, and our colleagues at Cambridge University Press, are delighted to announce that all illustrations reproduced in the Journal will now be published in full colour, at no cost to authors. Many illustrations are submitted in colour, particularly surgical photographs and photomicrographs, and we feel that this development will greatly enhance the value of papers when viewed either in print or electronically. The move to colour also coincides with a major redesign of the cover and paper layout of the print version of the JLO, which we hope will enhance the Journal's visual appeal.

Of course, colour is not the only feature of a good publication, and in this regard we would strongly disagree with the artist Henri Matisse, who said 'Seek the strongest colour effect possible... the content is of no importance'. The value of a journal's content is difficult to measure. The most frequently used parameter is the journal Impact Factor, which reflects the frequency of citation of a journal's content in other published work. We are delighted to report a further significant increase in the JLO Impact Factor for 2009 , the most recent year for which data are available. This continues the trend of a steady increase in the Journal's Impact Factor over the past eight years. The JLO is a journal with general appeal which contains a large amount of clinical content, and as such it will never achieve the high Impact Factors of those publications with a predominantly research content. Nevertheless, the steady increase in this measure is gratifying.

For 2011, we plan to introduce a new initiative, administered by Desmond Nunez, in which we reward authors for producing excellent papers, with a number of 'best paper' awards in various categories. The first authors of these papers will be invited to London to present their work at an annual scientific meeting. This initiative will replace the Travelling Scholarship awards that the Journal has previously given.

We are very aware that improvement in the Journal content must be matched by development in electronic means of communication. Over the past five years, our Web Editor, Nitesh Patel, has worked to achieve a fully functional journal website, available at www.jlo.co.uk. Nitesh has now stood down, and we thank him for all the time and expertise he has given to the Journal. The position of Web Editor has now been taken over by Vik Veer. Vik is in the process of a complete redesign of the JLO website, with the assistance of our colleagues at Tell Communications. Our objective in website development is to embrace this platform as a means of dispersal of educational material, particularly with regard to our colleagues in the developing world. Discussions are currently ongoing with a number of interested partners over collaborative ventures in the electronic field. 2009 also saw a change in the Cambridge University Press portal to the JLO (http://journals.cambridge.org/ action/displayJournal?jid=JLO), with a web page redesign and enhanced search facilities. The full archive of the Journal back to 1887 is available on-line, free to subscribers, and constitutes a fantastic resource for those interested in medical history.

We, as Editors, are fully aware of our short and transient position in the history of such a well established publication. During 2010, Edward Fisher was appointed as Joint Editor, replacing Guy Kenyon, who assumes the role of Chairman of JLO (1984) Ltd, the Journal's parent company. Guy will continue to be active in the Journal's affairs, having a particular interest in website development. Neil Weir has now stepped down from the Chairmanship of JLO (1984) Ltd. For many, Neil has been the face of the JLO in the recent era. Neil took over editorship of the JLO in 1992, and worked tirelessly on behalf of the Journal for many years. Much of the current success of the Journal is due to Neil, and the current Editors wish him well for the future in his many and varied ventures.

Also during 2010, the JLO Company Secretary, Michael Hellyar, retired after many years' invaluable service. The Editors and the board of JLO (1984) Ltd are immensely grateful to Michael, and appreciate the gentle and diligent manner in which he conducted the Journal's business. The role of Company Secretary has been taken on by Patrick Broadhurst.

Each year we express our appreciation for our Assistant Editors, who underpin the peer review process on which the maintenance of academic standards and integrity depends. The JLO differs from other journals in that it relies on a relatively small number of reviewers who undertake a considerable volume of work. All our Assistant Editors are leaders in their respective disciplines and are by nature busy people. We cannot overstate our appreciation of their work. We also appreciate the ongoing collaboration of the Royal Society of Medicine in the JLO/RSM 
Visiting Professors programme. In 2010, Professors Mike Benninger from Cleveland and Thomas Linder from Lucerne undertook a lecture tour of the UK, with presentations at The South West Laryngological Association in Gloucester and The Scottish Otolaryngological Society in Dunkeld, in addition to the RSM in London.

Finally, we must thank those who are most closely involved with the production of the Journal. Our colleagues at Cambridge University Press, particularly Daniel Edwards, Susan Perkins, Charlotte Porter and
Jacqueline Clark, have all made invaluable contributions, and work closely with the editorial team. Our greatest appreciation goes to the JLO editorial staff, Rosamund Greensted, Iona Copley, Lisa Colledge and Theresa Clarke, without whose diligence and dedication the Journal would not be produced.

We wish all our readers a successful 2011.

ROBIN YOUNGS EDWARD FISHER

Editors 